\title{
Ubiquitin Carboxyl-Terminal Hydrolase BAP1
}

National Cancer Institute

\section{Source}

National Cancer Institute. Ubiquitin Carboxyl-Terminal Hydrolase BAP1. NCI Thesaurus.

Code C21490.

Ubiquitin carboxyl-terminal hydrolase BAP1 (729 aa, $~ 80 \mathrm{kDa}$ ) is encoded by the human BAP1 gene. This protein plays a role in both the negative regulation of cell proliferation and the deubiquitination of histones. 